\title{
Conceptions of acculturation: A review and statement of critical issues
}

\author{
Maria Lopez-Class ${ }^{\mathrm{a}, *}$, Felipe González Castro ${ }^{\mathrm{b}, \mathrm{c}}$, Amelie G. Ramirez ${ }^{\mathrm{d}, \mathrm{e}}$ \\ a Department of Oncology, Lombardi Comprehensive Cancer, Center, Georgetown University, Washington, DC, USA \\ ${ }^{\mathrm{b}}$ Department of Psychology, Arizona State University, USA \\ ${ }^{c}$ Southwest Interdisciplinary Research Center, Arizona State University, USA \\ ${ }^{\mathrm{d}}$ Department of Epidemiology and Biostatistics, Institute for Health Promotion Research, The University of Texas Health Science Center at San Antonio, TX, USA

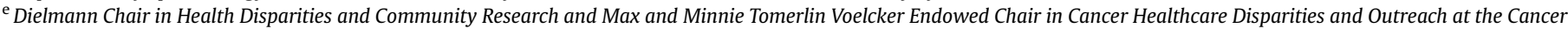 \\ Therapy E Research Center, The University of Texas Health Science Center at San Antonio, TX, USA
}

\section{A R T I C L E I N F O}

\section{Article history:}

Available online 24 March 2011

\section{Keywords:}

Acculturation

Latino subgroups

Contextual approaches

USA

Review

\begin{abstract}
A B S T R A C T
This article reviews evidence for re-conceptualizing acculturation status and acculturation process in health care research with United States (U.S.) Latino populations. Prior literature on acculturation has focused on: (a) acculturative change towards the dominant culture, (b) acculturation as it occurs with Mexican Americans, and (c) language as the principal component of acculturation. We review empirically based health research on acculturation and propose an ecodevelopmental framework for better understanding the process of acculturation. We then offer recommendations that may assist public health researchers, policymakers and program developers in better understanding "real world" acculturation. This includes understanding acculturation within this ecodevelopmental context for a more complete understanding of the acculturation process and its influences on health-related behaviors, with aims of reducing or eliminating health disparities in Latino populations.
\end{abstract}

Published by Elsevier Ltd.

\section{Introduction}

\section{Challenges in acculturation research}

The field of acculturation research is replete with complexity and ambiguities regarding the conceptualization and measurement of acculturation and in its association with health and well being. Some research has questioned these ambiguities as manifested across different ethnic groups, including: Asian Americans (Salant \& Launderdale, 2003), Cambodian refugees (Palinkas \& Pickwell, 1995), and Latinos (Rudmin, 2003). Some investigators have even concluded that acculturation should be abandoned in healthrelated research (Hunt, Schneider, \& Comer, 2004). However and by contrast, the processes of migration, sociocultural mobility, and acculturative change are ubiquitous sociocultural processes occurring worldwide. These must be examined to understand health issues and disparities affecting migrant and immigrant populations (Castro \& Nieri, 2010). Needed now are theory-driven, in-depth conceptualizations and analyses of the acculturative process and related longitudinal studies and methodologies (Bollen \& Curran,

\footnotetext{
* Corresponding author. Tel.: +1 301443 4480; fax: +1 3014801222.

E-mail address: lopezclassm@mail.nih.gov (M. Lopez-Class).
}

2006; Fuligni, Eccles, Barber, \& Clements, 2001) transcending the limitations of cross-sectional assessments of acculturation.

\section{Core issues regarding the construct of acculturation}

Acculturation was originally formulated by anthropologists as a group-level phenomenon involving cultural change and adaptation (Boas, 1888). Subsequently, the measurement and analysis of acculturation by psychologists introduced a change in its conceptualization (Cuellar, Arnold, \& Maldonado, 1995; Cuellar, Harris \& Jasso, 1980) that emphasized an individual level of analysis, thus introducing new approaches-yet also new problems. The present article examines issues in the conceptualization and measurement of acculturation as relevant to U.S. Latino populations, with suggestions for improving acculturation-focused research. This review is conducted using a four-pronged approach by presenting: (a) a historical overview of the concepts of acculturation and how these have been measured; (b) a review of the literature with a focus on existing measures of acculturation; (c) an analysis of emerging issues involving acculturation as relevant to health research; and (d) issues in the role of "contextual" circumstances to better understand "real world" acculturation as a process of sociocultural adaptation. Finally, recommendations will be offered for improving how research involving acculturative processes may be conducted. 


\section{Literature review: constructions of acculturation and its measurements}

\section{Historical overview of concepts of acculturation}

\section{Cultural contact}

Cultural change begins with contact between two individuals, groups, two different societies, or among diverse cultural systems. The cultural anthropologist, Herskovitz (1937), contended that any contact resulting in cultural change is best understood by examining both contemporary framing and historical contexts. This approach is corroborated by Glenn and Connell (1988) who also asserted the exploration of historical circumstances and developments will contextualize cultural differences at pre- and postcontact within a given society. These perspectives were further supported by Spiro (1955), a psychological anthropologist, who asserted that setting factors such as social mobility, religious preferences, family values, and personality, all promote acculturation.

\section{Initial conception of acculturation}

Generally, acculturation is a sociocultural process in which members of one cultural group adopt the beliefs and behaviors of another group (Hazuda, Stern, \& Haffner, 1988). From this simple definition many issues emerge. For example, acculturation is now regarded as a multi-dimensional process in which individuals and groups undergo stages of adjustment, as well as changes in several domains: in language, socioeconomic status, and/or cultural orientation (including changes in values and attitudes), etc., as they adapt to a new cultural environment (Olmedo, 1979). Sometimes these changes are extreme, particularly when the new host culture or setting consists of a vastly unfamiliar environment (Farver, Narang, \& Bhadha, 2002). Unfortunately, researchers have often-used varying conceptions and operationalizations of acculturation, making the term both broader in concept and also more specific (and perhaps more narrow) in terms of how it has been measured (Cuellar et al., 1980). Gordon (1978), for example, divided the process of acculturation into two stages: cultural assimilation and social assimilation. Based on wideranging variations in the conceptualization, measurement, and application of the construct of acculturation, conflicting outcomes and conclusions have emerged regarding the effects of acculturation on health-related outcomes. This has created confusion, ambiguity and incoherence in the field of acculturation research (Hunt et al., 2004).

These limitations have led researchers to acknowledge the need to modify and/or extend existing conceptions of acculturation and its measurement to accommodate the extant needs of Latinos who live within diverse, complex and often under-resourced communities (Lara, Gamboa, Kahramanian, Morales, \& Bautista, 2005). Gordon's (1978) conceptualization emphasizes a two-step process whereby the individual must first understand new and unfamiliar cultural values and customs encountered within a new host society, and then assimilates into that new society via involvement in social gatherings, clubs, or institutions (social assimilation). Other scholars have argued that individuals either acculturate, (get involved in a new society with no need for out-group acceptance), or assimilate, get involved in this new society with the need for out-group acceptance (Teske \& Nelson, 1974).

More recently, some researchers have viewed the process of acculturation as a continuous process occurring throughout a lifetime (Golden, 1988; Lang, Munoz, Bernal, \& Sorenson, 1982). For instance, individuals who migrate to a new country can exercise a multitude of personal preferences that generate a variety of acculturation pathways, including: (a) the avoidance of integration into the new society (separatism); (b) rejecting their native culture in favor of full involvement into the new society (assimilation); and (c) the integration of both cultures into a new blended cultural identity (biculturalism) (Farver et al., 2002; LaFromboise, Coleman, \& Gerton, 1993). Berry $(1997,2005)$ is the major proponent of a two-factor model that hypothesizes these outcomes with the addition of marginalization, which entails no involvement in either the native society or the new host society. However, this model has been criticized, suggesting that these four forms of acculturative change do not actually occur as indicated, and that perceptual, cognitive, social, and emotional processes also influence the manner in which acculturation occurs (Rudmin \& Ahmadzadeh, 2001). Other criticisms consider other variations in this process (Rudmin, 2003), including changes in personality (Triandis \& Suh, 2002). Although Berry's individualized model also emphasizes a person's active choices in their acculturative trajectory, it does not address the influences of major ecodevelopmental contextual variables (e.g., social networks, neighborhood resources, racial or ethnic discrimination) (Wandersman \& Nation, 1998), which also can greatly influence an individual's acculturative trajectory.

\section{Acculturation as measured via a variety of scales}

Just as acculturation has been conceptualized from several perspectives, many scales have been developed to measure acculturation. In general, early measures of acculturation consisted of single acculturation items, such as nativity or language (Olmedo, Martinez, \& Martinez, 1978), and these indicators focused mainly on Mexican Americans (Cuellar et al., 1980; Franco, 1983) and Cubans (Szapocznik, Scopetta, Kurtines, \& Aranalde, 1978). In the 1980 s, acculturation research not only considered acculturation as it occurs among various Latino subgroups, but also examined other factors that can change with acculturation (e.g., ethnic pride, ethnic food preferences), thus suggesting a multi-dimensional approach and the greater complexity of acculturation (Burnam, Telles, Karno, Hough, \& Escobar, 1987; Marin, Sabogal, Marin, Otero-Sabogal, \& Perez-Stable, 1987; Szapocznik et al., 1978). Then, in the 1990s, a bidimensional (two-factor) approach was introduced providing a major change in conceptualizing and measuring acculturation (Berry, 1994; Cortes, Rogler, \& Malgady, 1994).

\section{Two-factor models of acculturation}

Oetting and Beauvais (1991) proposed a two-factor "orthogonal" framework for conceptualizing acculturation, postulating that a person's involvement included two independent forms of cultural identification: (a) identification with the ethnic minority culture and (b) identification with the mainstream white American culture. In parallel with this approach, Berry (1997) also proposed a twofactor acculturation framework, a model with four possible acculturation outcomes: (a) marginalization (low affiliation with both cultures); (b) separation (high origin-culture affiliation, low newculture affiliation); (c) assimilation (high new-culture affiliation, low origin-culture affiliation); and (d) integration (high affiliation with both cultures). This two-factor reframing of acculturation has been useful, although it also has been criticized, in part for its lack of clarity over dimensional and categorical conceptions of these dimensions, and for its limitations in the production of substantive data that supports the contentions of this two-factor model. For example, the political, economic, and social contexts of an immigrant's country of origin introduce important contextual information to the study of acculturation, as they inform why individuals leave their country as well as how they will adapt in a new environment (Cabassa, 2003). This underscores the need to consider a multi-dimensional approach for assessing acculturation.

\section{Contexts and acculturation}

Today, more advanced conceptions of acculturation recognize the role of context as a determinant of the acculturation process (Alegria, 
2009; Lara et al., 2005). Context is introduced by ecological conditions, such as Latinos' place of residence, the size and form of a family unit, the school system, or the cultural features of an ethnic enclave (Bacallao \& Smokowski, 2009; Salant \& Launderdale, 2003). In this regard, context-specific behaviors may differentially influence the process of acculturative change (Berry, 1994). Acculturation also is greatly influenced by other contextual factors, such as the presence of various social constraints, including racial or ethnic discrimination (Clark, Anderson, Clark, \& Williams, 1999; Pantin, Schwartz, Sullivan, Prado, \& Szapocznik, 2004). In this regard, neighborhood characteristics (e.g., social cohesion, cultural enclaves) and geographic factors (e.g., population density) should be acknowledged as ecodevelopmental contextual influences on acculturation (Castro, Shaibi, \& Boehm-Smith, 2009) and also as influences on a person's health and well being (Alegria et al., 2006). Such contextual factors will affect the manner in which the process of acculturation proceeds, and thus the occurrence of differing "acculturation trajectories" (Castro, Marsiglia, Kulis, \& Kellison, 2010) as observed among diverse cases. Thus differing acculturation trajectories will occur in cases where a Latino immigrant family resides within a culturally-rich Latino enclave, as contrasted with their residence within a neighborhood in which they are the only Latino family. In addition, transient individuals who periodically travel to and from their native country may undergo a cyclical acculturation process that differs qualitatively from the typical process of acculturation. Furthermore, and in contrast with the hopeful expectations of many first-generation immigrant Latinos, second-generation Latinos may experience disappointment and a sense of exclusion ("othering") from the main society, based on experiences of discrimination or limited life chances (Viruell-Fuentes, 2007).

An innovative approach to the study of acculturation as a process of cultural change would be the study of variations in segmented assimilation trajectories, i.e., changes in acculturation and in socioeconomic mobility (Abraido-Lanza, Armbrister, Florez, \& Aguirre, 2006; Castro, Marsiglia et al., 2010). Segmented Assimilation Theory has described the conditions that govern variations in the assimilation trajectories of immigrants in their efforts towards integration into a new society (Portes \& Zhou, 1993).

Regarding acculturation and health, a major research issue is whether the process of acculturation is detrimental to the health of immigrants, or whether it is protective (Castro, 2007). This dilemma may be resolved by postulating the construct of "adaptive acculturation". Adaptive acculturation may consist of socioeconomic adaptation that enhances health under a trajectory of upward segmented assimilation (Castro, Marsiglia et al., 2010). Ostensibly, this favorable trajectory is protective against disease and psychological disorder, a form of cultural adaptation that affords "the best of both worlds".

\section{Emerging issues with the construct of acculturation in health studies}

Several concerns persist regarding the manner in which acculturation is conceptualized, thus consequently over how it should be measured. These concerns include the disproportionate role of language as used to measure acculturation. Other major measurement issues have included the use of restricted response options in scales that purport to measure acculturation, and the use of proxy measures of acculturation (e.g., nativity). This section provides a more in-depth analysis of these issues.

\section{Sole focus on language use}

The limits to measuring acculturation using language as its principal component is evident in several studies that have examined acculturation as related to: (a) health (DuBard \& Gizlice, 2008; Everhart, Ferketich, Browning, \& Wewers, 2009; Marin et al., 1987; Perez-Stable et al., 2001); (b) chronic disease (Eamranond et al., 2009; Mainous et al., 2006); and (c) health care practices (Ahluwalia, Ford, Link, \& Bolen, 2007; Heck, Franco, Jurkowski, \& Gorin, 2008; Mainous, Diaz, \& Geesey, 2008). As one example of a restricted range in measurement in a study on cigarette smoking (Zemore, 2006), investigators used dichotomous answer options ("0" to "no" answers and " 1 " to "yes"), thus limiting participants in the measurement of their English fluency, despite their actual level of mastery of the English language. Furthermore, using the language in which the survey was taken as a proxy for acculturation (DuBard \& Gizlice, 2008), has not accurately captured essential aspects of the concept of acculturation. In general, simple language measures do not aptly capture the complexity of language use, especially among bicultural individuals (Lara et al., 2005), let alone capturing other attitudinal, behavioral, and identity-related dimensions of acculturation. In this regard, using a single measure (language) can misclassify participants into inaccurate categories. In a more recent review, Thomson and Hoffman-Goetz (2009) acknowledge the significant limitations introduced by single acculturation scales (e.g., language), which includes a neglect of acculturative change within the context of personal networks, a change occurring on various dimensions including beliefs, values, attitudes, and behaviors.

\section{Research that misses ecological contexts}

Other research has focused on cross-sectional designs that fail to describe changes in values or practices occurring over time and across differing contexts and environments (Chirkov, 2009). For instance, in a study with Cuban immigrant families, rate of behavioral acculturation was conceptualized to include changes in language, customs, habits and lifestyles as a function of increasing length of exposure to the host culture (Szapocznik, Scopetta, \& Tillman, 1979). Similarly, among Mexican immigrant adolescents, conflict in family relationships may occur if all family members are not acculturating at the same rate (differential acculturation). This within-family variability in cultural orientations and preferences may thus produce stress and interpersonal conflicts (Bacallao \& Smokowski, 2009).

Recognizing personal and social contextual influences (e.g., family networks) that occur across the acculturation continuum is crucial, as these systemic family processes will influence how acculturation affects each family member's health and psychological well being (Thomson \& Hoffman-Goetz, 2009). One approach to capture the complex influences of individual and contextual processes within a family is to design research studies that utilize qualitative and/or a mixed methods approaches (Castro, Kellison, Boyd, \& Kopak, 2010). By observing immigrant families as they adjust to a new community or society, researchers can thus inductively discover patterns of cultural adaptation that would inform a more culturally-grounded analysis of the acculturation process (Chirkov, 2009).

\section{Binary/restricted options}

Similarly, a two-factor approach with limited response options within these two factors does not aptly address the experiences of migrants who interact with cultural groups other than the Latino and the White American cultures (Ahluwalia et al., 2007; Caetano, Ramisetty-Mikler, Wallisch, McGrath, \& Spence, 2008; KarrikerJaffe \& Zemore, 2009; Mainous et al., 2008). For example, when assessing linguistic acculturation, options that utilize Likert scales do not consider Latin American indigenous languages (e.g., Nahuatl) as an indigenous response that may occur among certain Latino respondents.

\section{Imperfect proxy measures}

The inclusion of sociodemographic characteristics (e.g., generation) as proxy measures of acculturation does not aptly capture the richness involved in understanding the construct of 
acculturation (Lara et al., 2005). In the past, the use of proxy measures -including generational status, age at migration, place of birth, and place of education-has assumed that acculturation can be approximated by the amount of exposure that individuals have to a dominant culture. For instance, in one study, U.S.-born participants were assigned a " 1 " score and foreign-born a " 0 " to measure immigrant status, thus broadly attributing greater acculturation status to those who were born in the United States (Detjen, Nieto, Trentham-Dietz, Fleming, \& Chasan-Taber, 2007). As a major problem, such proxy measures may misclassify Latinos into a single level of acculturation, not aptly making distinctions among variations in acculturation.

\section{Questionable construct validity}

Some studies have used a new scale in which certain subscales may exhibit poor internal consistency and/or include variables that may or may not accurately measure the concept of acculturation (Corral \& Landrine, 2008). For instance, classifying participants on a survey as "acculturated", if they respond to language spoken at home as only English or labeling them as "traditional", if they reply only Spanish spoken at home. Some studies mix and match indicators purporting to measure acculturation, yet they do not conduct the necessary psychometric analysis of scale reliability or factor structure to ascertain whether such composite indicators allow the additivity of such variables into a single scale (Lin, Bermudez, \& Tucker, 2003). Some constructed variables used to measure acculturation may involve conflicting levels of measurement (e.g., the commingling of nominal-level and interval-level items), thus raising questions about the validity of such indicators as a composite "measure" of acculturation (Masel, Rudkin \& Peek, 2006).

\section{Heterogeneous Latino populations}

Within contemporary U.S. society, researchers must reexamine the precise applicability and utility of previously validated scales as used with diverse Latino subcultural groups (Castro, Barrera et al., 2010) when these subgroups were not from previously studied groups used to validate a given acculturation scale. For example, groups from Mexico, Puerto Rico, or Cuba have been studied extensively in prior research (Borrayo \& Guarnaccia, 2000; Caetano et al., 2008; Fosados et al., 2007; Gordon-Larsen, Harris, Ward, \& Popkin, 2003), and acculturation scales validated with these groups may or may not be valid with other Latino groups (e.g., Dominicans). Many of the acculturation scales used in healthrelated research report high scale reliability, but do not show evidence of validity as applied to Central or South American Latinos (Fitzgerald, Damio, Segura-Perez, \& Perez-Escamilla, 2008; O’Malley, Kerner, Johnson, \& Mandelblatt, 1999) or across unique communities, such as various Latino subgroups now existing in new enclaves within the United States. Hence, a multi-dimensional model that accounts for within-group variations among Latinos and across Latino subgroups, as well as the interaction of environmental and neighborhood influences, is needed as it may better capture the actual process of acculturation.

\section{Directions for improving “Contextual" concepts and measures of acculturation}

\section{A broader conceptualization of acculturation}

The concept of acculturation to date has evolved and must account for changes occurring across many domains at differential rates and in different ways across diverse Latino subpopulations. Some acculturation-related factors or dimensions observable across various subpopulations include: (a) extent of language
(English) acquisition and proficiency of language usage; (b) the acquisition of dominant cultural-related behaviors (e.g., dietary habits); (c) relational behaviors, such as making friends or out-marriage with members of the dominant culture; and (d) membership in various sociocultural groups or organization from the dominant culture. As previously noted, these acculturative changes are influenced by social context, which emerges from such factors as: the location in which individuals live (e.g., communities), as well as by their daily interactions with others (social networks), adaptation processes (e.g., migration), and institutions (Pasick et al., 2009). In a special case of contextual analysis, context may be regarded as a moderator effect (Castro et al., 2009). That is, a certain outcome will occur within context A, whereas a completely different outcome will occur within context B. For example, a monolingual Spanish-speaking Mexican child may appear quiet and shy within context $A$ that involves exposure to a new group of White American English-speaking children his age. By contrast, that same child, minutes later, may appear loquacious and even emerge as a dynamic group leader in context B with exposure to his Mexican, Spanish-speaking peers and cousins. This contrast illustrates the moderator effects of two distinct social conditions, and thus the moderator effect of condition on behavior. In this regard, we offer some important considerations regarding environmental context, as this applies to better understanding acculturation within context.

\section{Influences of ethnic enclaves}

The English language can be acquired through many types of interactions, yet for some Latinos this dominant language is not easily acquired. An ethnic community contextualized by the availability of ethnic foods, vernacular language, and other familiar belongings can influence immigrants' opportunities and the acculturation process (Schwartz, Pantin, Sullivan, Prado, \& Szapocznik, 2006), including the process of English language acquisition. Bilingualism for Latinos involves the acquisition of the English language, coupled with the maintenance of Spanish, a combination that generally confers advantages, including facilitating interactions with diverse social groups, family cohesion, and positive mental health (Bacallao \& Smokowski, 2009).

\section{Dominant culture attitudes, values and behaviors}

The acquisition of certain behaviors, attitudes and values prevalent within American society may depend on the availability of healthy and unhealthy products within Latino communities. Food access has been influenced by where one lives (Lopez-Class \& Hosler, 2010) and by race (Morland, Wing, Diez Roux, \& Poole, 2002). Ayala, Baquero, and Klinger (2008) point to a gap in research regarding the importance of neighborhood environments on dietary health, and these community factors have implications for the development of obesity and diabetes among many Americans, including Latinos who acculturate into the mainstream American society. Contextual influences, such as availability and accessibility of cigarettes or alcohol within a community, also can facilitate the acquisition of health risk behaviors.

Among US-born children of immigrants, residential contexts can influence life chances, including those involving socioeconomic mobility and downward assimilation (e.g., dropping out of school, being unemployed) (Portes, Fernandez-Kelley, \& Haller, 2005). In this case, as indicated by Segmented Assimilation Theory, the effect of low human capital (a Mexican child from rural Chiapas, Mexico, who has low-literacy skills) coupled with exposure to bad school environments within a low-income barrio of East Los Angeles, as an ecodevelopmental context, can increase 
that child's probabilities of dropping out of school. Similarly, access to clinics has been associated with increased pap screenings among Latina immigrants (Fernandez-Esquer \& CardenasTuranzas, 2004) and decreased cervical screening for low-literacy Latinas (Garbers \& Chiasson, 2004). Hence, the varied resources that communities offer can influence the acculturation process in terms of the rates and ways of adopting selective aspects of American culture, while also maintaining native culture values and practices (Alegria, 2009).

\section{Influence of interpersonal relations among Latinos}

Familial and other forms of interpersonal values and relations are social factors that can affect the acculturation process. As Pasick et al. (2009) suggest, the extent to which behaviors occur is not solely related to familial influences, but also to the influences of new groups of persons. Latinos as a group value family bonds (familismo), as emphasized by other cultural values: personalismo (characterized by warmth, closeness, and empathy in one's relationship with others) (Campesino \& Schwartz, 2006) and confianza (trust) (Cuellar, Arnold, \& Gonzalez, 1995). The presence of a supportive network (e.g., relatives, neighbors) in a community high in social capital has been associated with breast-feeding initiation among Puerto-Rican Latinas (Anderson et al., 2004). Other research on social context has identified social networks as important to Latinos' emotional and physical well being (Insaf, Jurkowski, \& Alomar, 2010). Similarly, many Latinos value harmony in interpersonal relationships (e.g., simpatia) (Huerta \& Macario, 1999). Also, the value of interdependence (collectivity) (Oyserman, Coon, \& Kemmelmeier, 2002) is important to many Latinos. Hence, acculturation research should consider the influences of these traditional cultural values (e.g., simpatia, collectivity, interdependence), and how these values may change with acculturation (Cabassa, 2003; Marin \& Gamba, 2003). Thus the need exists to examine social networks and how changes within these networks can influence the acculturation process, including health (Thomson \& Hoffman-Goetz, 2009) and mental health outcomes (Ayon, Marsiglia, \& Bermudez-Parsai, 2010).

These observations as a whole underscore the importance of redefining acculturation as a multi-dimensional construct, as this involves changes in language, personality characteristics, healthrelated behaviors, and interpersonal relations as examined within the context of several ecodevelopmental levels (e.g., community/ neighborhood, family context, social networks), and not solely as a single personal trait (e.g., language proficiency) or a unidimensional process that occurs within a single individual domain. Given this more dynamic conceptualization of acculturation as a process of cultural adaptation, it will be important to step back and reassess the reliability and validity of current acculturation scales and reconsider the extent to which these operate as valid indicators of acculturation. Also, as this more "real world" conception of acculturation can better aid in developing healthrelated interventions to diminish health disparities, research investigators must recognize that Latino populations exhibit great diversity in where they initiate their acculturation trajectory (their acculturation intercept) (Castro, Marsiglia et al., 2010) and also in how much they can effect acculturative and socioeconomic changes, given their social and human capital. In other words, the "starting conditions" that various Latino individuals and populations experience must be considered in understanding variations in the process of cultural change and adaptation. Hence, an in-depth and "deep-structure" analysis (Resnicow, Soler, Braithwait, Ahluwalia, \& Butler, 2000) of how Latino traditional cultural practices may change given their residence within a community, may allow researchers to better design interventions that consider the needs and preferences of subcultural groups of Latinos (Castro, Balcazar, \& Cota, 2007).

\section{Trajectory models of acculturation change across time}

Recent studies have conducted prospective latent growth model analyses of acculturation and enculturation changes among adolescents (Knight et al., 2009). In this approach, acculturative changes among adolescents were examined in the domains of: (a) ethnic identity, (b) language use, and (c) affiliation with peers as examined across the time period of seven years (from ages 14-20). This analysis of acculturative changes illustrates the types of ecodevelopmental changes across time that should be conducted in more relevant studies of acculturation change process.

Similarly, a retrospective lifetime acculturation change approach has been conducted by Castro and colleagues to examine acculturative changes across a longer timeframe, albeit retrospectively, to understand variations in types of acculturative trajectories from childhood to adulthood. In this approach, indicators of acculturation (as measured by the often-used indicators of language spoken and read, mass media consumption, closest friends, and neighborhood or residence) were examined at the early life and current adult milestones. This approach identified four distinct acculturative and mobility groups and their trajectories, as these involved upward and downward sociocultural change (Castro et al., 2010). In a similar study of acculturative change in a sample of community parents, four acculturative change groups were identified based on their initial levels of acculturation in adolescence (acculturation intercepts), and their pattern of acculturative change from adolescence to adulthood: (a) enculturative change (a decrease in acculturation moving closer to Latino culture), (b) no change in acculturation across a lifetime, (c) small acculturation change (small increase in cultural change towards the mainstream American culture), and (d) large magnitudes of acculturative change (large changes towards the mainstream American culture) (Castro et al., 2011). These studies represent new approaches that examine the acculturation change process, thus moving beyond static conceptions of acculturation.

\section{Unique subgroups or social situations}

In an extension of such trajectory model analyses, researchers may assess the behavioral patterns of acculturation in atypical groups or individuals. For instance, for specific Latin American countries with a European cultural influence, acculturation into the mainstream American society may be easier for specific Latino subgroups, such as upper class Argentines (De La Rosa, Vega, \& Radisch, 2000). As a result, some immigrants may adapt differently based on their unique environmental experiences, cultural orientation or the political upheaval occurring in their country of origin, all which can influence the acculturation process and health outcomes (Palinkas \& Pickwell, 1995; Salant \& Launderdale, 2003). As another example, some African Americans and Latinos must contend with racism and discrimination, while certain Asians may experience post-migration trauma. More research is needed to understand not only intragroup heterogeneity (e.g., acculturated African American versus traditional African American), but also the unique migration histories among various immigrant groups, as these may operate as potent "starting conditions" and determinants of variations in acculturation trajectories (Organista, Organista, \& Kuraski, 2003). Today, as some Latinos face a resurgence of discrimination (Perreira, Fuligni, \& Potochnick, 2010) due to their actual or suspected status as being undocumented (being an "illegal alien"), and/or based on their appearance or accent, they will undergo acculturative stress 
and face social barriers to acculturation or assimilation into the mainstream American society (Gibbins et al., 2010).

\section{Barriers and suggestions for a multi-dimensional acculturation} inventory

Contemporary acculturation research has utilizeda multidimensional approach on acculturation that examines:(a) individualism-collectivism, (b) self-construal (e.g., independence versus interdependence), and (c) the prior dimensions of ethnic or cultural identifications (Schwartz, Unger, Zamboanga, \& Szapocznik, 2010; Schwartz, Weisskirch, et al., 2010). This approach argues against the use of simple language-based and/or other proxy measures of acculturation (e.g., generation status). Indeed, a major barrier to a new generation of acculturation research involves the persistent use of simplistic, unidimensional conceptualizations of acculturation and their measurement. This barrier can be surpassed by a conceptualization of acculturation which frames it within the context of "real world" acculturation changes. This process-related approach may generate a greater understanding of cultural changes and adaptation that are applicable to Latino health research.

This "real world" approach may be informed by actual case analyses of acculturative changes, as observed across three domains: (a) attitudes, (b) behaviors, and (c) values (Locke, 1998). For example, among immigrants, acculturation attitudes toward gender relations may change when they immigrate from traditional and restrictive cultural environments, and as they acculturate into the more permissive American society, where gender equality is more accepted. Similarly, acculturative changes in the behavioral domain may include changes in language acquisition, among other behavioral changes. Immigrants to the US from a non-Englishspeaking country who are monolingual speakers of their native language may undergo changes in language and expressive behaviors (and in related cognitions) as they acquire English-speaking skills. Similarly, values also may change. For example, among immigrants coming to the US from a collectivistic society, acculturation may increase their value and acceptance of individualism and self-directed growth, as a consequence of an ongoing exposure to the American values of freedom and liberty (Locke, 1998).

Finally, the integrative analysis of these acculturative changes, when examined concurrently across the attitudinal, behavioral, and value dimensions, would generate a more comprehensive analysis of variations in changes on these and other dimensions of acculturation. Such comprehensive dimensional analyses would provide a deeper level of understanding of the complexities that occur in the process of acculturation change, whereby some changes may occur faster in one dimension relative to another. Although the present dimensional overview introduces dimensions for a more comprehensive and robust analysis of the process of acculturation change, future studies that build on and expand on these directions may identify the most salient and essential dimensions among these, thus adding new knowledge for a better understanding and conceptualization of the complex process of acculturation.

In conclusion, Latino acculturation and health research can be strengthened if ecologically contextual factors are considered in the process of examining acculturation as a process of change (CarterPokras \& Bethune, 2009; McLeroy, Bibeau, Steckler, \& Glanz, 1988). Hence, context-specific factors within each level may be examined using an ecological model that considers not only individual-level influences (psychological well being, discrimination), but also contextual-level dimensions, including: community (Latino-based churches, ethnic enclaves), social capital (social cohesion), institutional (health care system), and policy (access to substance-based drugs) (McLeroy et al., 1988).

\section{Limitations}

Our findings should be interpreted within the context of the limitations of this review. Since our review focused on Latinos, we cannot make inferences regarding which components of acculturation are most salient for other ethnic groups. Although we searched for studies related to Latinos and acculturation in several databases, it is possible that we missed some studies. An additional limitation is the preponderance of studies related to Mexicans with limited studies conducted with other Latino subgroups.

\section{Final thoughts}

The acculturation experience is dynamic, multifaceted and complex. Under the process of acculturation, individuals and communities are constantly changing, and these micro-level changes are also influenced by macro-level events (e.g., immigration related legislation or ordinances) that can compromise or accelerate the acculturation process and their related acculturation and socioeconomic trajectories (Castro, Marsiglia et al., 2010). Hence, needed now are new methodologies/approaches that are both responsive to these variations in populations and contexts and that can model the actual dynamics of acculturation as a process of sociocultural change and adaptation across time. These approaches, if well grounded ecologically, will allow us to test specific hypotheses regarding the process of acculturation change, and may better inform the design of health-related interventions that aim to eliminate or reduce the health disparities that affect Latinos.

\section{Acknowledgments}

The authors would like to thank Jessika Angulo-Duarte and Cliff Depres for their assistance with manuscript preparation. This manuscript is supported by grants from the National Cancer Institute Grant \# 5U01CA114593-03, National Center on Minority Health and Health Disparities: Grant P20 MD 02316-01003, Felipe González Castro, Principal Investigator, and grant P20MD002316-03, Flavio F. Marsiglia, Principal Investigator, and grant, National Cancer Institute Grant \# U01CA114593, Amelie Ramirez, Principal Investigator. Dr. Lopez Class is currently affiliated with The National Institutes of Health. This research was completed while she was at Georgetown University, Lombardi Comprehensive Cancer Center.

\section{References}

Abraido-Lanza, A. F., Armbrister, A. N., Florez, K. R., \& Aguirre, A. N. (2006). Toward a theory-driven model of acculturation in public health research. American Journal of Public Health, 96(8), 1342-2146.

Ahluwalia, I. B., Ford, E. S., Link, M., \& Bolen, J. C. (2007). Acculturation, weight, and weight-related behaviors among Mexican Americans in the United States. Ethnicity and Disease, 17(4), 643-649.

Alegria, M. (2009). The challenge of acculturation measures: what are we missing? A commentary on Thomson \& Hoffman-Goetz. Social Science \& Medicine, 69(7), 996-998.

Alegria, M., Takeuchi, D., Canino, G., Duan, N., Shrout, P., Meng, X. L., et al. (2006). Considering context, place and culture: the national Latino and Asian American study. International Journal of Methods in Psychiatric Research, 13(4), 208-220.

Anderson, A. K. Damio, G. Himmelgreen, D. A., Peng Y. K. Segura-Perez, S., \& Perez-Escamilla, R. (2004). Social capital, acculturation, and breastfeeding initiation among Puerto Rican women in the United States. Journal of Human Lactation, 20(1), 39-45.

Ayala, G. X., Baquero, B., \& Klinger, S. (2008). A systematic review of the relationship between acculturation and diet among Latinos in the United States: implications for future research. Journal of the American Dietetic Association, 108(8) 1330-1344.

Ayon, C., Marsiglia, F., \& Bermudez-Parsai, M. (2010). Latino family mental health: exploring the role of discrimination and familismo. Journal of Community Psychology, 38(6), 742-756. 
Bacallao, M. L., \& Smokowski, P. R. (2009). Entre dos mundos/between two worlds bicultural development in context. Journal of Primary Prevention, 30, 421-451.

Berry, J. W. (1994). Acculturation and psychological adaptation: an overview. In A. Bouvy, F. J. R. Van de Vijver, P. Boski, \& P. Schmitz (Eds.), Journeys into cross cultural psychology (pp. 129-141). Amsterdam, Holland: Swets \& Zeitlinger.

Berry, J. W. (1997). Immigration, acculturation, and adaptation. Applied Psychology: An International Review, 46(1), 5-68.

Berry, J. W. (2005). Acculturation: living successfully in two cultures. International Journal of Intercultural Relations, 29, 697-712.

Boas, F. (1888). The aims of ethnology. In F. Boas (Ed.), Race, language, and culture (pp. 628-638). New York: Macmillan.

Bollen, K. A., \& Curran, P. J. (2006). Latent curve models: A structural equation approach. Wiley Series on Probability and Mathematical Statistics.

Borrayo, E. A., \& Guarnaccia, C. A. (2000). Differences in Mexican-born and U.S.-born women of Mexican descent regarding factors related to breast cancer screening behaviors. Health Care for Women International, 21(7), 559-613.

Burnam, M. A., Telles, C. A., Karno, M., Hough, R. L., \& Escobar, J. I. (1987). Measurement of acculturation in a community population of Mexican Americans. Hispanic Journal of Behavioral Sciences, 9(2), 105-130.

Cabassa, L. J. (2003). Measuring acculturation: where we are and where we need to do. Hispanic Journal of Behavioral Sciences, 25, 127-146.

Caetano, R., Ramisetty-Mikler, S., Wallisch, L. S., McGrath, C., \& Spence, R. T. (2008). Acculturation, drinking, and alcohol abuse and dependence among Hispanics in the Texas-Mexico border. Alcoholism: Clinical and Experimental Research, 32(2), 314-321

Campesino, M., \& Schwartz, G. E. (2006). Spirituality among Latinas/Os: implications of culture in conceptualization and measurement. Advances in Nursing Science, 29(1), 69-81.

Carter-Pokras, O., \& Bethune, L. (2009). Defining and measuring acculturation: a systematic review of public health studies with Hispanic populations in the United States. A commentary on Thomson and Hoffman-Goetz. Social Science E Medicine, 69(7), 992-995.

Castro, F. G. (2007). Is acculturation really detrimental to health? American Journal of Public Health, 97(7), 1162.

Castro, F. G., Balcazar, H., \& Cota, M. (2007). Health promotion in Latino populations: program planning, development, and evaluation. In M. V. Kline, \& R. M. Huff (Eds.), Promoting health in multicultural populations (2nd ed.). (pp. 222-253) Thousand Oaks, CA: Sage.

Castro, F. G., Barrera, M., \& Holleran Steiker, L. K. (2010). Issues and challenges in the design of culturally-adapted evidence-based interventions. Annual Review of Clinical Psychology, 6, 213-239.

Castro, F. G., Boyd, S., Garvey, M., Kellison, S. G., Marsiglia, F., \& Parsai, M. (2011) Latino youths' intentions for substance use: parental acculturation trajectories and parent-youth relationship factors. In R. Perez-Escamilla, \& H. MelgarQuinones (Eds.), Latino children wellness and health. Houston, TX: Arte Publico Press.

Castro, F. G., Kellison, J. G., Boyd, S. J., \& Kopak, A. (2010). A methodology for conducting integrative mixed methods research and data analyses. Journal of Mixed Methods Research, 4(4), 342-360.

Castro, F. G., Marsiglia, F. F., Kulis, S., \& Kellison, J. G. (2010). Lifetime segmented assimilation trajectories and health outcomes in Latino and other community residents. American Journal of Public Health, 100(4), 669-676.

Castro, F. G., \& Nieri, T. (2010). Cultural factors in drug use etiology: concepts, methods and recent findings. In L. M. Scheier (Ed.), Handbook of drug use etiology: Theory, methods, and empirical findings (pp. 305-324). Washington, DC: American Psychological Association.

Castro, F. G., Shaibi, G. Q., \& Boehm-Smith, E. (2009). Ecodevelopmental contexts for preventing type 2 diabetes in Latino and other racial/ethnic minority populations. Journal of Behavioral Medicine, 32(1), 89-105.

Chirkov, V. (2009). Critical psychology of acculturation: what do we study and how do we study it, when we investigate acculturation? International Journal of Intercultural Relations, 33, 94-105.

Clark, R., Anderson, N. D., Clark, V. R., \& Williams, D. R. (1999). Racism as a stressor for African Americans. American Psychologist, 54, 805-816.

Corral, I., \& Landrine, H. (2008). Acculturation and ethnic-minority health behavior: a test of the operant model. Health Psychology, 27(6), 737-745.

Cortes, D. E., Rogler, L. H., \& Malgady, R. G. (1994). Biculturality among Puerto Rican adults in the United States. American Journal of Community Psychology, 22(5), 707-721.

Cuellar, I., Arnold, B., \& Gonzalez, G. (1995). Cognitive referents of acculturation: assessment of cultural constructs in Mexican Americans. Journal of Community Psychology, 23, 339-356.

Cuellar, I., Arnold, B., \& Maldonado, R. (1995). Acculturation rating scale for Mexican Americans-II: a revision of the original ARMSA scale. Hispanic Journal of Behavioral Sciences, 17(3), 275-304.

Cuellar, I., Harris, L. C., \& Jasso, R. (1980). An acculturation scale for Mexican American normal and clinical populations. Hispanic Journal of Behavioral Sciences, 2(3), 199-217.

De La Rosa, M., Vega, R., \& Radisch, M. A. (2000). The role of acculturation in the substance abuse behavior of African-American and Latino adolescents: advances, issues, and recommendations. Journal of Psychoactive Drugs, 32(1), 33-40.

Detjen, M. G., Nieto, J., Trentham-Dietz, A., Fleming, M., \& Chasan-Taber, L. (2007). Acculturation and cigarette smoking among pregnant Hispanic women residing in the United States. American Journal of Public Health, 97(11), 2040-2047.

DuBard, C. A., \& Gizlice, Z. (2008). Language spoken and differences in health status, access to care, and receipt of preventive services among US Hispanics. American Journal of Public Health, 98(11), 2021-2028.

Eamranond, P. P., Legedza, A. T. R., Diez Roux, A. V., Kandula, N. R., Palmas, W., et al. (2009). Association between language and risk factor levels among Hispanic adults with hypertension, hypercholesterolemia, or diabetes. American Heart Journal, 157(1), 53-59.

Everhart, J., Ferketich, A. K., Browning, K., \& Wewers, M. E. (2009). Acculturation and misclassification of tobacco use status among Hispanic men and women in the United States. Nicotine \& Tobacco Research, 11(3), 240-247.

Farver, J. A., Narang, S. K., \& Bhadha, B. R. (2002). East meets west: ethnic identity, acculturation, and conflict in Asian Indian families. Journal of Family Psychology, 16(3), 338-350.

Fernandez-Esquer, M., \& Cardenas-Turanzas, M. (2004). Cervical cancer screening among Latinas recently immigrated to the United States. Preventive Medicine, $38,529-535$.

Fitzgerald, N., Damio, G., Segura-Perez, S., \& Perez-Escamilla, R. (2008). Nutrition knowledge, food label use, and food intake patterns among Latinas with and without type 2 diabetes. Journal of the American Dietetic Association, 108(6), 960-967.

Fosados, R., McClain, A., Ritt-Olson, A., Sussman, S., Soto, D., BaezcondeGarbanati, L., et al. (2007). The influence of acculturation on drug and alcohol use in a sample of adolescents. Addictive Behaviors, 32(12), 2990-3004.

Franco, J. N. (1983). An acculturation scale for Mexican-American children. The Journal of General Psychology, 108, 175-181.

Fuligni, A. J., Eccles, J. S., Barber, B. L., \& Clements, P. (2001). Early adolescent peer orientation and adjustment during high school. Developmental Psychology, 37(1), 28-36.

Garbers, S., \& Chiasson, M. A. (2004). Inadequate functional health literacy in Spanish as a barrier to cervical cancer screening among immigrant Latinas in New York City. Preventing Chronic Disease, 1(4), 1-10.

Gibbins, F. X., Etcheverry, P. E., Stock, M. L., Gerrard, M., Weng, C.-Y., et al. (2010). Exploring the link between racial discrimination and substance use: what mediates? What buffers? Journal of Personality and Social Psychology, 99(5), 785-801.

Glenn, D., \& Connell, J. (1988). Acculturation and health in the highlands of Papua New Guinea. Current Anthropology, 29(2), 273-293.

Golden, J. G. (1988). Assimilation or biculturalism - which way to adapt to American life?. In Annual Meeting of the National association for Asian and Pacific American education [conference]. Denver, CO. 7-9 April 1988.

Gordon, M. M. (1978). Human nature, class and ethnicity. New York: Oxford University Press.

Gordon-Larsen, P., Harris, K. M., Ward, D. S., \& Popkin, B. M. (2003). Acculturation and overweight-related behaviors among Hispanic immigrants to the US: the national longitudinal study of adolescent health. Social Science $\mathcal{E}$ Medicine, 57(11), 2023-2034.

Hazuda, H. P., Stern, M. P., \& Haffner, S. M. (1988). Acculturation and assimilation among Mexican Americans: scales and population-based data. Social Science Quarterly, 69(3), 687-706.

Heck, J. E., Franco, R., Jurkowski, J. M., \& Gorin, S. S. (2008). Awareness of genetic testing for cancer among United States Hispanics: the role of acculturation. Community Genetics, 11(1), 36-42.

Herskovitz, M. J. (1937). The significance of the study of acculturation for anthropology. American Anthropologist, 39(2), 259-264.

Huerta, E. E., \& Macario, E. (1999). Communicating health risk to ethnic groups: researching Hispanics as a case study. Journal of the National Cancer Institute Monographs, 25, 23-26.

Hunt, L. M., Schneider, S., \& Comer, B. (2004). Should "acculturation" be a variable in health research? Social Science $\mathcal{E}$ Medicine, 59(5), 973-986.

Insaf, T. Z., Jurkowski, J. M., \& Alomar, L. (2010). Social cultural factors influencing delay in seeking routine health care among Latinas: a community-based participatory research study. Ethnicity and Disease, 20(2), 148-154.

Karriker-Jaffe, K. J., \& Zemore, S. E. (2009). Associations between acculturation and alcohol consumption of Latino men in the United States. Journal of Studies on Alcohol and Drugs, 70(1), 27-31.

Knight, G. P., Vargas-Chanes, D., Losoya, S. H., Cota-Robles, S., Chassin, L., \& Lee, J. M. (2009). Acculturation and enculturation trajectories among Mexican American adolescent offenders. Journal of Research in Adolescence, 19, 625-653.

LaFromboise, T., Coleman, H. L. K., \& Gerton, J. (1993). Psychological impact of biculturalism: evidence and theory. Psychological Bulletin, 114(3), 395-412.

Lang, J., Munoz, R., Bernal, G., \& Sorenson, J. (1982). Quality of life and psychological well being in a bicultural Latino community. Hispanic Journal of Behavioral Sciences, 4(4), 433-450.

Lara, M., Gamboa, C., Kahramanian, M. I., Morales, L. S., \& Bautista, D. E. (2005). Acculturation and Latino health in the United States: a review of the literature and its sociopolitical context. Annual Review of Public Health, 26, 367-397.

Lin, H., Bermudez, O. I., \& Tucker, K. L. (2003). Dietary patterns of Hispanic elders are associated with acculturation and obesity. American Society for Nutritional Sciences, 133, 3651-3657.

Locke, C. D. (1998). Increasing multicultural understanding: A comprehensive model (2nd ed.). Thousand Oaks, CA: Sage. 
Lopez-Class, M., \& Hosler, A. S. (2010). Assessment of community food resources: a Latino neighborhood study in upstate New York. Journal of Poverty, 14(4), 369-381.

Mainous, A. G., Diaz, V. A., \& Geesey, M. E. (2008). Acculturation and healthy lifestyle among Latinos with diabetes. Annals of Family Medicine, 6(2), 131-137.

Mainous, A. G., Majeed, A., Koopman, R. J., Baker, R., Everett, C. J., Tilley, B. C., et al. (2006). Acculturation and diabetes among Hispanics: evidence from the 1999-2002 national health and nutrition examination survey. Public Health Reports, 121(1), 60-66.

Marin, G., \& Gamba, J. R. (2003). Acculturation and changes in cultural values. In K. M. Chun, P. B. Organista, \& G. Marin (Eds.), Acculturation: Advances in theory, measurement, and applied research (pp. 83-94), Washington: DC.

Marin, G., Sabogal, F., Marin, B. V., Otero-Sabogal, R., \& Perez-Stable, E. J. (1987) Development of a short acculturation scale for Hispanics. Hispanic Journal of Behavioral Sciences, 9(2), 183-205.

Masel, M. C., Rudkin, L. L., \& Peek, M. K. (2006). Examining the role of acculturation in health behaviors of older Mexican Americans. American Journal of Health Behavior, 30(6), 684-699.

McLeroy, K. R., Bibeau, D., Steckler, A., \& Glanz, K. (1988). An ecological perspective on health promotion programs. Health Promotion Quarterly, 15(4), 351-377.

Morland, K., Wing, S., Diez Roux, A. D., \& Poole, C. (2002). Neighborhood characteristics associated with the location of food stores and food service places. American Journal of Preventive Medicine, 22(1), 23-29.

O'Malley, A. S., Kerner, J., Johnson, A. E., \& Mandelblatt, J. (1999). Acculturation and breast cancer screening among Hispanic women in New York City. American Journal of Public Health, 89(2), 219-227.

Oetting, E. R., \& Beauvais, F. (1991). Orthogonal cultural identification theory: the cultural identification of minority adolescents. Substance Use E Misuse, 25(12), 655-685.

Olmedo, E. L. (1979). Acculturation: a psychometric perspective. American Psychologist, 34(11), 1061-1070.

Olmedo, E. L., Martinez, J. L., \& Martinez, S. R. (1978). Measure of acculturation for Chicano adolescents. Psychological Reports, 42(1), 159-170.

Organista, P. B., Organista, K. C., \& Kuraski, K. (2003). The relationship between acculturation and ethnic minority mental health. In K. M. Chun, P. B. Organista, \& G. Marin (Eds.), Acculturation: Advances in theory, measurement, and applied research (pp. 139-161), Washington: DC.

Oyserman, D., Coon, H. M., \& Kemmelmeier, M. (2002). Rethinking individualism and collectivism: evaluation of theoretical assumptions and meta-analyses. Psychological Bulletin, 128, 3-72.

Palinkas, L., \& Pickwell, S. M. (1995). Acculturation as a risk factor for chronic disease among Cambodian refugees in the United States. Social Science \& Medicine, 40(12), 1643-1653.

Pantin, H., Schwartz, S. J., Sullivan, S., Prado, G., \& Szapocznik, J. (2004). Ecodevelopmental HIV prevention program for Hispanic adolescents. American Journal of Orthopsychiatry, 74, 545-588.

Pasick, R. J., Barker, J. C., Otero-Sabogal, R., Burke, N. J., Joseph, G., \& Guerra, C (2009). Intention, subjective norms, and cancer screening in the context of relational culture. Health Education \& Behavior, 36(5), 91-110.

Perez-Stable, E. J., Ramirez, A., Villareal, R., Talavera, G. A., Trapido, E., Suarez, L., et al. (2001). Cigarette smoking behavior among US Latino men and women from different countries of origin. American Journal of Public Health, 91(9), 1424-1430.
Perreira, K. M., Fuligni, A., \& Potochnick, S. (2010). Fitting in: the roles of social acceptance and discrimination in shaping the academic motivations of Latino youth in the U.S. Southeast. Journal of Social Issues, 66, 131-153.

Portes, A., Fernandez-Kelley, P., \& Haller, W. (2005). Segmented assimilation on the ground: the new second generation in early adulthood. Ethnic and Racial Studies, 28(6), 1000-1040.

Portes, A., \& Zhou, M. (1993). The new second generation: segmented assimilation and its variants. Annals of the American Academy of Political and Social Science, 530, 74-96.

Resnicow, K., Soler, R., Braithwait, R. L., Ahluwalia, J. S., \& Butler, J. (2000). Cultural sensitivity in substance abuse prevention. Journal of Community Psychology, 28, 271-290.

Rudmin, F. W. (2003). Critical history of the acculturation psychology of assimilation, separation, integration, and marginalization. Review of General Psychology, 7, 3-37.

Rudmin, F. W., \& Ahmadzadeh, V. (2001). Psychometric critique of acculturation psychology: the case of Iranian migrants in Norway. Scandinavian Journal of Psychology, 42(1), 41-46.

Salant, T., \& Launderdale, D. S. (2003). Measuring culture: a critical review of acculturation and health in Asian immigrant populations. Social Science $E$ Medicine, 57, 71-90.

Schwartz, S. J., Pantin, H., Sullivan, S., Prado, G., \& Szapocznik, J. (2006). Nativity and years in the receiving culture as markers of acculturation in ethnic enclaves. Journal of Cross Cultural Psychology, 37(3), 345-353.

Schwartz, S. J., Unger, J. B., Zamboanga, B. L., \& Szapocznik, J. (2010). Rethinking the concept of acculturation: implications for theory and research. American Psychologist, 65, 237-251.

Schwartz, S. J., Weisskirch, R. S., Zamboanga, B. L., Castillo, L. G., Ham, L. S., QueLam, H., et al. (2010). Dimensions of acculturation: associations with health risk behaviors among college students from immigrant families. Journal of Counseling Psychology, 58, 27-41.

Spiro, M. E. (1955). The acculturation of American ethnic groups. American Anthropologist, 55(6), 1240-1252.

Szapocznik, J., Scopetta, M. A., Kurtines, W., \& Aranalde, M. D. (1978). Theory and measurement of acculturation. Interamerican Journal of Psychology, 12(2), 113-130.

Szapocznik, J., Scopetta, M. A., \& Tillman, W. (1979). What changes what remains the same and what affects acculturative change in Cuban immigrant families. In J. Szapocznik, \& M. C. Herrera (Eds.), Cuban-Americans: Acculturation, adjustment and the family. Washington, DC: COSSMHO.

Teske, R. H. C., \& Nelson, B. H. (1974). Acculturation and assimilation: a clarification. American Ethnologist, 1(2), 351-367.

Thomson, M. D. \& Hoffman-Goetz, L. (2009). Defining and measuring acculturation: a systematic review of public health studies with Hispanic populations in the United States. Social Science \& Medicine, 69(7), 983-991.

Triandis, H., \& Suh, E. M. (2002). Cultural influences on personality. Annual Review of Psychology, 53, 133-160.

Viruell-Fuentes, E. A. (2007). Beyond acculturation: immigration, discrimination, and health research among Mexicans in the United States. Social Science E Medicine, 65(7), 1524-1535.

Wandersman, A., \& Nation, M. (1998). Urban neighborhoods and mental health psychological contributions to understanding toxicity, resilience, and interventions. American Psychologist, 53, 648-649.

Zemore, S. E. (2006). Re-examining whether and why acculturation relates to drinking outcomes in a rigorous, national survey of Latinos. Alcoholism: Clinical and Experimental Research, 29(12), 2144-2153. 